\title{
LISTS AND KEYS OF THE CEDAR RUSTS OF THE WORLD ${ }^{1}$
}

\author{
Frank D. KerN \\ Emeritus Professor of Botany, The Pennsylvania State University
}

These lists and keys have been prepared in connection with a monographic study of the cedar rusts (genus Gymnosporangium) of the world. It is the author's belief that such a presentation will be found to have value in the hands of other workers.

Gymnosporangium was described by Hedwig. f. in de Candolle (Lamarck \& Candolle; Flore Francais 3rd Ed. tome 2, pp. 216 and 217). One species is autoecious ( $G$. bermudianum) on Juniperus, two species have uredial stages (G. nootkatense in the United States and G. gaeumanni in Switzerland). With these exceptions the species are heteroecious and demicyclic. Most of the species where the life cycles are known have their aecial stages (form-genus Roestelia) on the members of the Rosaceae tribe Pomeae or family Malaceae (depending upon the classification used). Exceptions are $G$. ellisii on the bayberry family, $G$. speciosum on the saxifrage family, and $G$. exterum and $G$. vauqueliniae on the rose family. A few are known only in the telial stage and several are known only in the aecial (roestelial) stage.

The species possess such variable characters that a generic description is difficult.

The aecia are chiefly roestelioid, i.e., with elongated peridia, cylindrical or cornute, dehiscent by apical or lateral rupture; the aeciospore wall is usually colored, with numerous scattered pores. The telia may be variously shaped, applanate or pulvinate, laterally compressed or wedge-shaped, or terete, sometimes irregular, and usually expand when moistened due to the gelatinization of the long pedicels. In most species there can be distinguished darker, thick-walled teliospores and lighter, thin-walled teliospores.

It is believed that the lists and keys are self-explanatory. The drawings and photographs are included not so much to present the characters of certain species but rather to illustrate the meaning of some of the descriptive terms. It seems needless to point out that this sort of effort has its limitations, however. It must be acknowledged that the keys are not strictly dichotomous and that final separations may be difficult or confusing. In any event a contribution is being offered toward the identities, relations, and ranges of the various species.

In the check lists citations are included for the 55 valid species in Gymnosporangium, and the 11 names of the form species known in the aecial stage only. A bibliography of publications on the genus Gymnosporangium is very long. These selected references are presented as an aid to those interested in the taxonomy of the genus :

1 Contribution No. 288 of the Department of Botany and Plant Pathology, The Pennsylvania State University. 
Arthur, J. C. 1934. Manual of the rusts in United States and Canada. 1-438.

Bernaux, Paul. 1956. Contribution a l'étude de la biologie des Gymnosporangium. Ann. Epiphyt. 7: 1-210.

Crowell, Ivan H. 1940. The geographical distribution of the genus Gymnosporangium. Canad. Jour. Res. C. 18: 469-488.

Cummins, G. B. \& Ling, L. 1950. An index of the plant rusts recorded for continental China and Manchuria. Pl. Dis. Reporter Suppl. 196: 520-556.

Cummins, G. B. \& Stevenson, J. A. 1956. A check list of North American rust fungi (Uredinales). Pl. Dis. Reporter Suppl. 240: 109-193.

Eriksson, J. 1918. Die Schwedischen Gymnosporangien ihr Wirtswechsel und ihre Spezialisierung. K. Svens. Vet-Acad. Handl. 59: 1-82.

Fischer, Ed. 1891. Ueber Gymnosporangium sabinae (Dicks.) und Gymnosporangium confusum Plowright. Zeitschr. Pflanzenkr. 1: 193-208, 260-283. 1895. Die Zugehörigkeit von Aecidium penicillatum. Hedwigia 34: 1-6.

Grasso, V. 1956. I Gymnosporangium di alcuni boschi della Toseana e le loro forme pienoecidiche. Ann. Accad. Ital. Sci. Foresta 5: 21-89.

Hiratsuka, N. 1936, 1937. Gymnosporangium of Japan. I. Bot. Mag. Tokyo 50: 481-488. II. 549-555. III. 593-599. IV. 661-668. V. 51: 1-8.

Jørstad, I. 1942. Some cyprian Uredinales. Nytt Mag. Naturvid. B. 83: 191-229.

Hylander, N., Jørstad, I. \& Nannfeldt, J. A. 1953. Enumeratio uredinearum Seandinavicarum. Opera Bot. 1: 1-102.

Kern, Frank D. 1910. The morphology of the peridial cells in the Roesteliae. Bot. Gaz. 49: 445452.

1911. A biologic and taxonomic study of the genus Gymnosporangium. Bull. N. Y. Bot. Gard. 7: 391-483.

1960 [1962]. Changing concepts in the genus Gymnosporangium. Mycologia 52: 837-844.

Prince, Alton E. 1946. The biology of Gymnosporangium nidus-avis Thaxter. Farlowia 2: 475525.

Tanaka, T. 1922. New Japanese fungi. Notes and translations-XII. Mycologia 14: 282-295.

\section{CHECK LIST OF THE SPECIES OF GYMNOSPORANGIUM}

(* The twelve species preceded by an asterisk known in telial stage only.)

amelanchieris Ed. Fisch. ex Kern. Bull. N. Y. Bot. Gard. 7: 443. 1911.

asiaticum Miyabe ex Yamada. Shokubutsu Byorigaku (Plant Pathology)

Tokyo Hakubunkwan, M. 37, 9: 304-306. 1904.

*atlanticum Guyot \& Malencon. Trav. Inst. Scient. Cherifien Ser. Bot. 11: 15. 1957.

bermudianum Earle in Seymour \& Earle. Economic Fungi No. 249. 1893.

betheli Kern. Bull. Torrey Club 34: 459. 1907.

biseptatum Ell. Bull. Torrey Club 5 : 46. 1874.

clavariiforme (Pers.) DC. Fl. Fr. 2: 217. 1805.

clavipes (Cke, \& Pk.) Cke. \& Pk. in Pk. Ann. Rep. N. Y. St. Mus. 25: 89. 1873. confusum Plowr. Brit. Ured. and Ustil. p. 232. 1889.

corniculans Kern in Arth. Mycologia 2: 236. 1910.

*corniforme Sawada ex Hiratsuka f. Bot. Mag. Tokyo 50 : 554. 1936.

cornutum Arth. ex Kern. Bull. N. Y. Bot. Gard. 7: 444. 1911.

cunninghamianum Barcl. Sci. Mem. Med. Off. India 5: 78. 1890.

cupressi Long \& Goodding in Long. Bot. Gaz. 72: 39. 1921.

davisii Kern. Bull. Torrey Club 35: 507. 1908.

*effusum Kern. Bull. N. Y. Bot. Gard. 7: 459. 1911.

ellisii (Berk.) Ell. N. Am. Fungi No. 271. 1877.

exiguum Kern. Bull. Torrey Club 35 : 508. 1908.

exterum Arth. \& Kern in Arth. Mycologia 1: 254. 1909.

floriforme Thaxt. in Kern. Bull. Torrey Club 35: 503. 1908. 
*formosanum Hiratsuka f. \& Hashioka. Bot. Mag. Tokyo 49: 21. 1935.

fraternum Kern. Bull. N. Y. Bot. Gard. 7: 439. 1911.

fuscum DC. Fl. Fr. 2: 217. 1805.

fusisporum Ed. Fisch. Mitt. Naturforsch. Ges. Bern 1917: 73.1918.

*gaeumanni H. Zogg. Ber. Schweiz. Bot. Ges. 59 : 426.1949.

globosum Farl. The Gymnosporangia or Cedar Apples of the U. S. p. 34. 1880. gracile Pat. Bull. Soc. Mycol. Fr. 18: 46. 1902.

harknessianum Kern ex Arth. N. Am. Flora 7: 737. 1926.

hemisphericum K. Hara. Dainippon Sanrin Kwaiho (Jour. Forest. Soc. Japan)

419 : 16-18. 1917.

hyalinum Kern ex Cummins. Mycologia 48: 603. 1956.

inconspicuum Kern. Bull. Torrey Club 34: 461. 1907.

japonicum Sydow. Hedwigia Beibl. 38: 141. 1899.

juniperi-virginianae Schw. Shr. Nat. Ges. Leipzig 1: 74. 1822.

kernianum Bethel. Mycologia 3: 157. 1911.

libocedri (P. Henn.) Kern. Bull. Torrey Club 35: 509. 1908.

*meridissimum Crowell. Canad. Jour. Res. C. 18: 11-12. 1940.

* minus Crowell. Canad. Jour. Res. C. 18: 10. 1940.

miyabei Yamada \& Miyake. Shok. Zass. (Bot. Mag.) Tokyo 22: 23. 1908.

*multiporum Kern. Mycologia 1: 210. 1909.

nelsoni Arth. Bull. Torrey Club 28: 665. 1901.

nidus-avis Thaxt. Conn. Agr. Exp. Sta. Bull. 107: 3. 1891.

nipponicum Yamada in Hiratsuka f. Mem. Tottori Agr. Coll. 3: 143. 1935.

nootkatense Arth. Am. Jour. Bot. 3: 44. 1916.

* padmarense Balfour-Brown. Bull. Brit. Mus. (Nat. Hist.) Bot. 1: 205. 1955.

* paraphysatum Viennot-Bourgin. Revue de Mycol. 25: 304.1960.

shiraianum K. Hara. Byochu-gai Zasshi (Jour. Pl. Prot.) 62 : 684. 1919.

speciosum Pk. Bot. Gaz. 4: 217. 1879.

*taianum sp. nov. (see below).

torminali-juniperinum Ed. Fisch. Zeitschr. Bot. 2: 759. 1910.

trachysorum Kern in Arth. Mycologia 2 : 237-238. 1910.

tremelloides Hartig. Lehrb. Kaumkrankh. p. 55. 1882.

*tsingchensis Wei. Bot. Bull. Acad. Sinica 1: 210. 1947.

turkestanicum Tranz. Consp. Ured. U. S. S. R. p. 77. 1939.

vauqueliniae Long \& Goodding. Mycologia 31: 671. 1939.

yamadae Miyabe ex Yamada in Omori. G. Shokubutzu Byorigaku (Plant Pathology) Tokyo Hakubunkwan, M. 37, p. 306-308. 1904.

\section{Gymnosporangium taianum Kern, sp. nov.}

Teliis caulicoli, in ramulis viridibus ligneisque evolutis, matrice leviter tumescenti, ordinatis in ligneis, solitariis in viridibus; hemisphaericis, $1.5-3 \mathrm{~mm}$ diam., vel oblongis et linguiformibus, $2-3 \mathrm{~mm}$ altis, fusco-brunneis ("carob brown") ; teliosporis medio 1-septatis, ellipsoideis vel oblongo-ellipsoideis, 24-30 $\times 53-67 \mu$, episporio $2-3 \mu$, cinnamomeo-brunneo, vel late ellipsoideis, 29-36 $\times$ $57-63 \mu$, episporio 3-4 $\mu$, castaneo-brunneo; poris 4-6 vel pluribus in quaque cellula, in uno zono transverso prope a septo, aut in duobus zonis, ad apicem et ad basim uno vel duobus tantum; pedicello elongato.

Type. On Cupressus duclouxiana, Yunnan, Kunming, China, F. L. Tai et al. 8097 (Herbarium, Plant Pathology, National Tsing Hua University, Kunming). 
Tai (Farlowia 3: 107. 1947) described this species in English. He knew that it did not agree with Gymnosporangium cunninghamianum but nevertheless referred it to that species. It is herein described as a new species. Tai cites three numbers, 8097, 8162, 8197. I designate 8097 as the type. Tai illustrated two teliospores (Farlowia 3: 137, fig. 8, 1947).

\section{KNOWN IN AECIAL STAGE ONLY}

distortum (Gymnosporangium) Arth. \& Cumm. Mycologia 25 : 400. 1933.

fenzelianum (Gymnosporangium) Tai \& Cheo, Bull. Chinese Bot. Soc. 3: 60. 1937. guatemalianum (Gymnosporangium) Crowell, Canad. Jour. Res. C. 18: 11. 1940. leve (Gymnosporangium) Crowell, Jour. Arnold Arb. 17: 50. 1936.

magnum (Gymnosporangium) Crowell, Jour. Arnold Arb. 17: 50. 1936.

malyi (Gymnosporangium) Picbauer, Glasnika Zemaljskeg. Muz. Bozni Hercegorini 41 : 32.1929.

nanwutianum (Gymnosporangium) Tai \& Cheo, Bull. Chinese Bot. Soc. 3: 60. 1937.

patulum (Aecidium) Sydow, Ann. Mycol. 5: 506. 1907.

pourthiaeae (Aecidium) Sydow, Mem. Herb. Boiss. 4: 3. 1900.

sikangense (Gymnosporangium) Petrak, Acta Horti Gothob. 17: 120. 1947.

wenshanense (Gymnosporangium) Tai, Farlowia 3: 108. 1947.

\section{DISPOSITION OF NON-VALID NAMES IN THE GENUS GYMNOSPORANGIUM}

(A partial list only)

Synonyms

aurantiacum Chev.

aurantiacum Sydow

blasdaleanum Kern

botryapites Kern

chinense Long.

durum Kern

germinale Kern

gracilens Kern \& Bethel

haraeanum Sydow

idetae Yarnada

juniperi Link

juniperinum Mart.

juvenescens Kern

koreanse Jacks.

macropus Link

mespili Kern

myricatum Fromme

orientale Sydow

oxycedri Bres.

penicillatum Liro

photiniae Kern

sabinae Wint.

solenoides Kern
Accepted names

cornutum

libocedri

libocedri

biseptatum

asiaticum

nelsoni

clavipes

speciosum

asiaticum

amelanchieris

cornutum

tremelloides

nidus-avis

asiaticum

juniperi-virginianae

confusum

ellisii

clavariiforme

confusum

tremelloides

japonicum

fuscum

miyabei 
Synonyms

sorbi Kern

spiniferum Sydow

tauricum Erikss.

transformans Kern

tubulatum Kern

yamadai Miyabe
Accepted names

nootkatense

asiaticum

confusum

fraternum

betheli

yamadae

\section{GEOGRAPHICAL DISTRIBUTION BY CONTINENTS}

asiaticum (introduced)

bermudianum

betheli

biseptatum

clavariiforme

clavipes

corniculans

cornutum

cupressi

davisii

effusum

ellisii

exiguum

exterum

floriforme

fraternum

fuscum (introduced)

globosum

gracile

amelanchieris

clavariiforme

confusum

cornutum

fuscum

fusisporum

gaeumanni

amelanchieris

asiaticum

clavariiforme

confusum

corniforme

cornutum

cunninghamianum

formosanum
NORTH AMERICA

\author{
harknessianum \\ hyalinum \\ inconspicuum \\ japonicum (introduced) \\ juniperi-virginianae \\ kernianum \\ libocedri \\ meridissimum \\ multiporum \\ nelsoni \\ nidus-avis \\ nootkatense \\ speciosum \\ tremelloides \\ trachysorum \\ vauqueliniae
}

Known in aecial stage only guatemalianum

EUROPE

gracile

minus

torminali-juniperinum

tremelloides

Known in aecial stage only malyi

ASIA

fuscum

hemisphericum

japonicum

miyabei

nipponicum

padmarense

paraphysatum 


\section{ASIA (continued)}

\section{shiraianum \\ taianum \\ tsingchensis \\ turkestanicum \\ yamadae}

Known in aecial stage only distortum

\author{
atlanticum \\ clavariiforme \\ confusum
}

\author{
fenzelianum \\ leve \\ magnum \\ nanwutianum \\ patulum \\ pourthiaeae \\ sikangense \\ wenshanense
}

\section{AFRICA}

\author{
cornutum ? \\ fuscum \\ gracile
}

\section{ANALYTIC KEYS}

\section{Aecial Stage Exclusively Considered}

1. Aecia cupulate, peridium short, lacerate or erose.

2. Aeciospore-wall thicker above.

2. Aeciospore-wall evenly thick.

3. Aeciospore-wall pale brown.

(Aecidium) patulum.

3. Aeciospore-wall pale yellow.

magnum.

4. Wall thin $(1-1.5 \mu)$.

4. Wall thick $(3-4 \mu)$.

libocedri.

3. Aeciospore-wall nearly colorless.

5. Wall thin $(1 \mu)$.

5. Wall medium thick $(2-3 \mu)$.

6. Wall strongly verrucose.

6. Wall minutely verrucose.

nootkatense.

(Aecidium) pourthiaeae. $\cdot$

1. Aecia roestelioid.

7. Peridium retaining tubular or cornute form, not much altered by dehiscence.

8. Peridium finally dehiscent at apex, slightly or not lacerate.

9. Peridial cells verrucose.

10. Side-walls of peridial cells verrucose only on inner third.

11. Aeciospore-wall pale yellow, 2-2.5 $\mu$.

11. Aeciospore-wall cinnamon-brown, 1-1.5 $\mu$.

inconspicuum. miyabei.

10. Side-walls of peridial cells verrucose over entire surface.

- 12. Aeciospore-wall finely verrucose, $2-2.5 \mu$.

12. Aeciospore-wall rugose-verrucose, 2.5-3 $\mu$.

harknessianum. malyi.

9. Peridial cells verruculose.

13. Aeciospores $20-26 \times 23-31 \mu$, wall $2-3 \mu$.

13. Aeciospores $18-23 \times 19-28 \mu$, wall $1.5-2 \mu$.

9. Peridial cells closely papillose.

9. Peridial cells subspinulose.

9. Peridial cells spinulose.

14. Peridial cells rather long $(80-120 \mu)$.

15. Aeciospore-wall verruculose.

15. Aeciospore-wall smooth.

14. Peridial cells not so long $(50-90 \mu)$.

16. Peridium hypophyllous, $1-3 \mathrm{~mm}$ high.

16. Peridium hypophyllous and fructicolous, $2-6 \mathrm{~mm}$.

9. Peridial cells semi-rugose, with elongated papillae.

ellisii. wenshanense.

9. Peridial cells rugose.

17. Inner and side walls rather sparsely or coarsely rugose.

18. Inner and side walls $7-9 \mu$ thick, aeciospore-wall $1.5-2 \mu$.

amelanchieris. 
18. Inner and side walls $2-2.5 \mu$ thick, aeciospore-wall $2-2.5 \mu$.

17. Inner and side walls densely and rather finely rugose.

19. Aeciospore-wall dark cinnamon-brown, aeciospores $18-25 \times 20-29 \mu$.

hemisphericum.

19. Aeciospore-wall yellowish brown, aeciospores $18-23 \times 23-38 \mu$. fenzelianum.

8. Peridium tardily or not at all dehiscent at apex, with slits along the sides.

20. Peridial cells tuberculate.

21. Papillae on side-walls short, aeciospore-wall $1.5-2.5 \mu$.

21. Papillae on side-walls blunt, aeciospore-wall 2.5-3.5 $\mu$.

20. Peridial cells verrucose with roundish or oval papillae.

20. Peridial cells verrucose-rugose with irregular papillae.

20. Peridial cells rugose with closely set ridge-like papillae.

20. Peridial cells smooth.

cornutum.

7. Peridium more or less tubular, altered by becoming lacerate or fimbriate.

22. Peridium strongly revolute.

23. Peridial cells somewhat curved when wet, side-walls rugose nearly to outer side.

23. Peridial cells strongly eurved when wet, side-walls sparsely rugose on inner half.

juniperi-virginianae.

22. Peridium spreading or more or less erect after dehiscence.

24. Peridial cells smooth.

24. Peridial cells sculptured.

25. Peridial cells subspinulose.

25. Peridial cells verrucose.

26. Peridial cells rhomboidal.

27. Aeciospore-wall chestnut-brown.

27. Aeciospore-wall pale-yellow.

28. Aeciospores 21-24 × 24-29 $\mu$.

28. Aeciospores 21-32 × 24-39 $\mu$.

hyalinum.

yamadae.

kernianum. corniculans.

cupressi.

davisii.

biseptatum.

26. Peridial cells linear $(150-300 \mu)$, much curved or coiled when wet.

26. Peridial cells oblong $(80-130 \mu)$, slightly curved when wet.

trachysorum.

turkestanicum.

speciosum. clavipes.

fraternum. clavariiforme or gracile.

25. Peridial cells rugose.

27. Peridium short ( 0.5 to 1 or $2 \mathrm{~mm}$ high).

28. Aeciospores small $(17-22 \times 19-26 \mu)$.

29. Aeciospore-wall cinnamon-brown, 2.5-3.5 $\mu$.

29. Aeciospore-wall very pale cinnamon-brown $2-2.5 \mu$.

28. Aeciospores medium-sized $(18-27 \times 19-35 \mu)$.

30. Aeciospore-wall rugose $(2-2.5 \mu)$.

30. Aeciospore-wall verrucose.

31. Aeciospore-wall yellow-brown, 3-5 $\mu$.

31. Aeciospore-wall light chestnut-brown, 1.5-2 $\mu$.

31. Aeciospore-wall dark chestnut-brown $(2-2.5 \mu)$.

28. Aeciospores large $(28-35 \times 30-45 \mu)$.

27. Peridium more or less elongated (1.5-4 $\mathrm{mm}$ high).

32. Aeciospores small $(15-19 \times 18-25 \mu)$, wall $1.5-2 \mu$.

32. Aeciospores larger $(15-26 \times 18-32 \mu)$, wall $2.5-3.5 \mu$.

27. Peridium further elongated (2-5-6 $\mathrm{mm}$ or more).

33. Aeciospores large $(18-24 \times 19-35 \mu)$.

33. Aeciospores small $(16-18 \times 18-23 \mu$.

33. Aeciospores medium-sized $(18-24 \times 19-30 \mu)$.

34. Aeciospore-wall cinnamon-brown, $1.5-2.5 \mu$.

34. Aeciospore-wall chestnut-brown, 2.5-3 $\mu$.

confusum. exterum.

distortum.

sikangense. cunninghamianum.

* bermudianum.

tremelloides.

globosum. nidus-avis.

fusisporum. shiraianum.

torminali-juniperinum. betheli. 7. Peridium balanoid, rupturing along sides, apex remaining bluntly conical. fuscum.

\section{Telial Stage Exclusively Considered}

1. Telia foliicolous, or on green stems, with no or slight hypertrophy.

2. Telia causing fasciation of the branches (witches' brooms).

3. 'Witches' brooms globose, with scale-like leaves, sori bluntly conical.

kernianum.

* This is the only known species which is autoecious; here the aecia are on Juniperus. 
3. Witches' brooms brush-like, usually with juvenile leaves, sori hemispheric. nidus-avis.

2. Telia not causing fasciation.

4. Telia hemispheric.

5. Telia chiefly epiphyllous.

6. Teliospores 2-celled, rarely 3 - or 1-celled.

shiraianum.

6. Teliospores 2-celled.

7. Teliospores with hyaline papillae.

8. Teliospores 35-49 $\mu$ long, papillae noticeable.

8. Teliospores 40-55 $\mu$ long, papillae large.

7. Teliospores without hyaline papillae.

5. Telia arising between the scale-like leaves.

4. Telia musciform.

4. Telia pulvinate.

9. Telia sometimes causing corniform elongation of leaves.

9. Telia without deformation of leaves or branches.

10. Teliospores 2-3 or 4-celled, uredinia with paraphysis-like structures.

10. Teliospores 2-5-celled, uredinia unknown.

paraphysatum.

10. Teliospores 2-celled.

11. Teliospores pastilliform, squarish or irregular.

11. Teliospores ellipsoid.

12. Teliospores with wall thicker above.

12. Teliospores with wall evenly thick.

13. Teliospores small ( $35-45 \mu$ long).

13. Teliospores large $(55-80 \mu$ long $)$.

12. Teliospores with hyaline papillae over pores (sori also caulicolous).

libocedri.

formosanum.

fraternum.

asiaticum inconspicuum.

4. Telia tongue-shaped, or conical, teliospores $42-63 \mu$ long.

4. Telia wedge-shaped, teliospores $37-53 \mu$ long.

4. Telia truncate, teliospores 45-72 $\mu$ long.

exiguum.

betheli (or nelsoni).

harknessianum.

4. Telia unknown; uredia present, teliospores intermixed, 2-celled.

14. Teliospores with papillae; urediospores with 6-8 pores.

14. Teliospores without papillae, urediospores with 2 pores.

1. Telia caulicolous, on smaller branches, with little hypertrophy.

15. Teliospores with 1-2 pores in each cell, near the septum.

15. Teliospores with 4-6 pores, in one or two transverse zones.

1. Telia caulicolous, on witches' brooms.

16. Telia hemispheric, reddish brown.

17. Teliospore-wall cinnamon-brown, often slightly thicker above.

17. Teliospore-wall hyaline to fulvous, uniform.

16. Telia cylindrical, orange-color.

18. Teliospores 2-celled.

18. Teliospores 2-5-celled.

gaeumanni.

nootkatense.

cunninghamianum.

taianum.

nidus-avis. vauqueliniae.

gracile. ellisii.

1. Telia caulicolous, on galls or gall-like excrescences.

19. Galls rotund, small, telia pulvinate.

20. Telia following aecia, cinnamon-brown, spores $34-50 \mu$ long.

20. Telia without aecia, chestnut-brown, teliospores $48-60 \mu$ long. of large branches or trunks).

21. Telia laterally compressed, scattered.

22. Telia irregularly tongue-shaped, often crenate.

22. Telia wedge-shaped.

23. Teliospores with papillae over the pores.

23. Teliospores without papillae.

bermudianum.

meridissimum.

1. Telia irregularly compressed, often confluent.

21. Telia terete.

24. Telia somewhat conic, chestnut-brown.

25. Teliospores with slight hyaline thickenings over the pores.

25. Teliospores with wall uniformly thick.

corniculans.

24. Telia subcylindric.

26. Telia cylindric-acuminate, 10-20 mm long, golden-brown. juniperi-virginianae.

26. Telia mostly tapering, 6-10 $\mathrm{mm}$ long, chestnut-brown.

trachysorum. 
21. Telia pulvinate, crowded, often confluent.

turkestanicum.

1. Telia caulicolous, on fusiform enlargements.

27. Enlargements slight, mostly on smaller branches.

28. Telia cylindrical, teliospores 2-celled.

padmarense.

28. Telia applanate, teliospores with pedicels terete.

29. Teliospores with hyaline papillae over the pores.

cornutum.

29. Teliospores without hyaline papillae.

30. Teliospores with wall thicker above $(3-5 \mu)$.

30. Teliospores with wall uniform.

hyalinum. amelanchieris.

28. Telia hemispheric, teliospores with pedicels carotiform.

28. Telia conic, or laterally compressed. clavipes.

7. Enlargements irregularly fusiform, knot-like or gall-like on larger branches.

31. Telia applanate.

32. Teliospores 1-3-celled (40-80 $\mu$ long).

32. Teliospores 2-celled (40-60 $\mu$ long).

31. Telia wedge-shaped (sori also on galls, and foliicolous).

27. Enlargements gradually fusiform, mostly on woody branches.

33. Telia hemispheric mostly small and definite.

34. Teliospores 2-4-celled.

34. Teliospores 2-celled.

35. Pores 2, near the septum, or three in upper cell, 1 apical.

35. Pores usually 4 in a band near the septum, or with 1 or 2 additional in each cell.

33. Telia applanate, or pulvinate, usually large and indefinite.

36. Teliospores small, $32-42 \mu$ long.

36. Teliospores large, 45-60 $\mu$ long.

33. Telia terete, eylindric, or slightly compressed.

33. Telia cristiform, irregularly crenate above.

33. Telia conic, or laterally compressed.

37. Teliospores 1-celled.

37. Teliospores 2-celled.

38. Teliospores ellipsoid, 42-51 $\mu$ long.

38. Teliospores fusiform, falcate or sigmoid, 46-90 $\mu$ long.

33. Telia tongue-shaped, often crenate above.

33. Telia wedge-shaped, often irregular and lacunose.

39. Teliospores medium-sized (42-55 $\mu$ long).

39. Teliospores rather large $(44-67 \mu$ long $)$.

miyabei.

tremelloides.

betheli.

biseptatum.

nidus-avis.

atlanticum.

minus.

clavariiforme.

speciosum.

tsingchensis.

confusum or fuscum.

fusisporum.

cupressi.

effusum.

japonicum.

1. Telia caulicolous, on larger branches, or main trunk, often with some hypertrophy.

40. Telia pulvinate.

40. Telia laterally compressed.

41. Teliospores 1-celled, telia dentiform.

meridissimum.

41. Teliospores 2-celled.

42. Telia tongue-shaped, crenate, 4-6 mm high.

42. Telia wedge-shaped, 3-4 $\mathrm{mm}$ high.

42. Telia often irregular and lacunose, 7-10 $\mathrm{mm}$ high.

41. Teliospores 2-3-celled, telia cristiform.

tsingchensis.

cupressi.
betheli.
effusum.
speciosum.

\section{HOST KEYS}

\section{Hosts Harboring Aecial Phase}

\section{On Amelanchier}

1. Aecia aecidioid.

libocedri.

1. Aecia roestelioid.

2. Peridium retaining tubular form, not much altered by dehiscence.

3. Peridium dehiscent at apex, slightly or not lacerate.

4. Peridial cells verrucose.

5. Side walls of peridial cells verrucose on inner third.

5. Side walls of peridial cells verrucose over entire surface.

4. Peridial cells rugose.

4. Peridial cells semi-rugose, with elongated papillae.

4. Peridial cells spinulose.

inconspicuum.

harknessianum.

amelanchieris. nelsoni.

guatemalianum. 
3. Peridium tardily or not at all dehiscent at apex.

6. Peridial cells verrucose with roundish or oval papillae.

6. Peridial cells verrucose-rugose with irregular papillae.

corniculans. cupressi.

6. Peridial cells smooth.

2. Peridium more or less tubular, altered by becoming lacerate and spreading.

7. Peridial cells rugose.

7. Peridial cells verrucose.

8. Aeciospore-wall pale yellow.

8. Aeciospore-wall cinnamon-brown.

nidus-avis.

clavipes. gracile or clavariiforme.

\section{On Aronia}

1. Aecia roestelioid, peridium retaining tubular or cornute form.

davisii.

1. Aecia roestelioid, peridium becoming lacerate and spreading.

2. Peridial cells rhomboidal $(45-90 \mu)$.

2. Peridial cells oblong $(80-130 \mu)$, slightly curved when wet.

2. Peridial cells linear $(150-300 \mu)$, curved or coiled when wet.

clavipes. clavariiforme. fraternum.

\section{On Chaenomeles}

1. Aecia aecidioid.

libocedri.

1. Aecia roestelioid.

2. Aeciospore-wall pale yellow, $21-32 \times 24-39 \mu$.

clavipes.

2. Aeciospore-wall cinnamon-brown, 18-26 × 21-30 $\mu$.

3. Peridial cells rugose, with long ridges.

3. Peridial cells verruculose, with long papillae.

nidus-avis. asiaticum.

\section{On Comptonia (See Myrica)}

On Cormus (See Sorbus or Malus)

\section{On Cotoneaster}

1. Aecia roestelioid, peridium retaining tubular form, peridial cells spinulose, aeciospores verrucose.

1. Aecia roestelioid, peridium becoming lacerate or fimbriate.

2. Peridial cells rugose, aeciospore-wall rugose.

2. Peridial cells rugose, aeciospore-wall verrucose.

3. Aeciospores 19-22 × 19-26 $\mu$.

3. Aeciospores $18-24 \times 19-35 \mu$.

2. Peridial cells papillose.

2. Peridial cells verrucose.

3. Aeciospore-wall cinnamon-brown.

3. Aeciospore-wall pale yellow.

nanwutianum.

distortum.

confusum. fusisporum. sikangense.

clavariiforme. clavipes.

\section{On Crataegus}

1. Aecia aecidioid.

2. Aeciospore-wall uniformly thick.

3. Asciospores small $(12-20 \times 14-23 \mu)$.

libocedri.

3. Aeciospores large $(24-29 \times 30-32 \mu)$.

magnum.

patulum.

1. Aecia roestelioid.

4. Peridium remaining more or less tubular, somewhat lacerate.

5. Peridial cells tuberculate.

5. Peridial cells strongly spinulose.

5. Peridial cells verrucose-rugose.

5. Peridial cells rugose.

kernianum. exiguum. malyi. globosum.

4. Peridium losing tubular form, deeply lacerate.

6. Peridial cells sculptured.

7. Peridial cells verrucose.

8. Aeciospore-wall pale yellow.

8. Aeciospore-wall cinnamon-brown.

clavipes.

7. Peridial cells rugose.

9. Inner and side walls moderately rugose, rather thick $(3-6 \mu)$.

9. Inner and side walls strongly rugose, thick $(5-7 \mu)$. 
7. Peridial cells subspinulose.

trachysorum.

6. Peridial cells smooth.

4. Peridium strongly revolute.

hyalinum.

floriforme.

\section{On Cydonia}

1. Aecia aecidioid.

libocedri.

1. Aecia roestelioid.

2. Peridium rupturing at apex and more or less along the sides.

3. Peridial cells verruculose with long papillae.

asiaticum.

3. Peridial cells tuberculate with blunt papillae.

kernianum.

2. Peridium losing tubular form, becoming lacerate and spreading.

4. Peridial cells verrucose.

5. Aeciospore-wall pale yellow, coarsely verrucose.

clavipes.

5. Aeciospore-wall cinnamon-brown, moderately verrucose. clavariiforme or gracile.

4. Peridial cells rugose, linear-rhomboid; aeciospores medium-sized (18-28 $\mu$ ).

6. Inner and side walls strongly rugose with ridges of varying length. confusum.

6. Inner and side walls rugose with long narrow ridges interspersed with roundish papillae.

nidus-avis.

4. Peridial cells rugose, rhomboid; aeciospores large (28-45 $\mu)$.

tremelloides.

\section{On Fendlera}

Aecia roestelioid, peridium tubular, peridial cells verrucose, aeciospores 21-24 $\times$

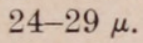

speciosum.

\section{On Gillenia}

Aecia roestelioid, peridium soon lacerate and spreading, peridial cells rugose, aeciospores $17-21 \times 21-26 \mu$.

exterum.

\section{On Heteromeles}

Aecia roestelioid, peridium not spreading much, peridial cells spinulose.

exiguum.

\section{On Juniperus}

Aecia roestelioid, on galls, peridium lacerate, aeciospores $16-19 \times 19-29 \mu$. bermudianum.

\section{On Macromeles (See Malus)}

\section{On Malus}

1. Aecia aecidioid.

2. Aeciospores small $(18-20 \times 14-23 \mu)$.

2. Aeciospores large $(23-27 \times 27-39 \mu)$.

libocedri. nootkatense.

1. Aecia roestelioid.

3. Peridium conical or subcylindrical, dehiscent only at apex 1-1.5 $\mathrm{mm}$ high.

3. Peridium cornute, retaining shape, $3-5 \mathrm{~mm}$ high.

hemisphericum.

3. Peridium tubular, spreading or more or less erect after rupturing.

4. Peridial cells tuberculate. cornutum.

4. Peridial cells verrucose.

5. Aeciospores $21-32 \times 24-39 \mu$, wall yellow.

5. Aeciospores 18-24 diam., wall cinnamon-brown.

4. Peridial cells spinulose.

4. Peridial cells rugose.

6. Aeciospores small $(15-19 \times 18-25 \mu)$, wall thin $(1-2 \mu)$.

6. Aeciospores medium $(18-23 \times 23-38 \mu)$, wall medium $(1.5-2.5 \mu)$.

6. Aeciospores large $(28-35 \times 30-45 \mu)$, wall thick $(3-5 \mu)$.

3. Peridium strongly revolute ofter dehiscence.

yamadae.

clavipes. miyabei.

leve.

globosum.

fenzelianum. tremelloides. juniperi-virginianae.

\section{On Mespilus}

Aecia roestelioid, becoming lacerate, peridial cells rugose.

confusum.

On Micromeles (See Sorbus) 


\section{On Myrica}

Aecia aecidioid, peridial cells with thick outer wall, smooth, thinner inner wall, verrucose, spores $24-30 \times 27-34 \mu$.

ellisii.

\section{On Peraphyllum}

1. Aecia roestelioid.

2. Peridium rupturing at apex and along the sides, peridial cells semi-rugose. nelsoni.

2. Peridium rupturing at apex, not lacerate along sides, peridial cells verrucose. inconspicuum.

\section{On Philadelphus}

Aecia roestelioid, peridium tubular, peridial cells verrucose.

speciosum.

On Photinia (Pourthiaea)

1. Aecia roestelioid.

2. Peridial cells subspinulose.

2. Peridial cells verruculose.

japonicum. asiaticum.

1. Aecia cupulate.

3. Aeciospores medium-sized (18-23 $\times 23-30 \mu$ ), wall $2-3 \mu$.

3. Aeciospores small (17-19 $\times 19-24 \mu)$, wall $1 \mu$ (Aecidium).

wenshanense. pourthiaeae.

\section{On Pyrus}

1. Aecia aecidioid.

2. Aeciospores small $(18-20 \times 14-23 \mu)$.

libocedri.

2. Aeciospores large $(23-27 \times 27-39 \mu)$. nootkatense.

1. Aecia roestelioid.

3. Peridium losing tubular form, becoming lacerate and spreading.

4. Peridial cells rhomboid in side-view.

5. Peridial cells rugose, aeciospores brown.

5. Peridial cells verrucose, aeciospores yellow.

cunninghamianum. clavipes.

4. Peridial cells linear-rhomboid in side-view.

6. Peridial cells verrucose.

clavariiforme.

6. Peridial cells rugose.

7. Inner and side walls moderately rugose, medium $3-5 \mu$.

7. Inner and side walls strongly rugose, thick, 5-7 $\mu$.

3. Peridium retaining tubular form, rupturing at apex.

8. Peridium cylindrical, long $(3-6 \mathrm{~mm})$.

8. Peridium cylindrical, medium $(2-5 \mathrm{~mm})$.

9. Peridial cells tuberculate.

9. Peridial cells rugose or parallel-striated.

3. Peridium balanoid, rupturing along sides, apex remaining bluntly conic.

globosum. confusum.

asiaticum.

kernianum. shiraianum. fuscum.

\section{On Sorbus}

1. Aecia aecidioid.

2. Aeciospores small $(18-20 \times 14-23 \mu)$.

2. Aeciospores large $(23-27 \times 27-39 \mu)$.

libocedri.

1. Aecia roestelioid.

3. Peridium retaining tubular form, dehiscent at apex.

4. Peridial cells rugose.

4. Peridial cells verrucose.

4. Peridial cells verruculose.

3. Peridium losing tubular form becoming lacerate or spreading.

5. Peridial cells rugose.

6. Peridia elongated (1.5-4 $\mathrm{mm}$ high).

7. Aeciospores small $(15-19 \times 18-25 \mu)$, wall $1.5-2 \mu$.

7. Aeciospores medium sized $(15-26 \times 18-32 \mu)$, wall $2-3.5 \mu$.

globosum. nidus-avis.

6. Peridia elongated ( $2-5$ or $6 \mathrm{~mm}$ or more).

8. Aeciospores very large $(28-35 \times 30-45 \mu)$, wall $3-5 \mu$.

8. Aeciospores small $(18-24 \times 24-27 \mu)$, wall $1.5-2.5 \mu$.

5. Peridial cells verrucose.

tremelloides. torminali-juniperinum. turkestanicum. 


\section{Hosts Harboring Telial Phase}

\section{On Chamaecyparis}

1. Telia foliicolous, without hypertrophy, teliospores 2-celled.

2. Teliospores with medium cinnamon-brown walls, thicker above, $3-5 \mu$.

2. Teliospores with thin, lemon-yellow walls, uniform, 1-1.5 $\mu$.

fraternum. nootkatense.

1. Telia caulicolous, causing more or less hypertrophy.

3. Enlargements of stems slight or gradually fusiform.

4. Telia pulvinate, teliospores 2-celled.

4. Telia hemispheric, teliospores 2-4-celled.

4. Telia terete, slender, teliospores 2-5-celled.

3. Enlargements irregular, knotty, teliospores 1-3-celled.

1. Telia often causing fasciation of the branches.

hyalinum.

biseptatum.

ellisii.

miyabei.

ellisii.

\section{On Cupressus}

1. Telia caulicolous, on smaller branches only, with little hypertrophy.

2. Teliospores with 1-2 pores in each cell, near the septum.

cunninghamianum.

2. Teliospores with 4-6 or more pores, in one transverse zone near the septum or in two zones, those near apex or base only two in number.

1. Telia caulicolous, on smaller branches, with fusiform swellings.

taianum.

1. Telia caulicolous, extending to larger branches and main trunk, with hypertrophy.

3. Swellings fusiform to subglobose galls, telia becoming tongue-shaped and irregular, teliospores 2-celled, 16-27 × 30-60 $\mu$.

3. Swellings at first rotund galls, later fusiform swellings, telia pulvinate, teliospores 2-celled, 24-28 $\times$ 48-60 $\mu$.

meridissimum.

3. Swellings fusoid, on branches of various ages, telia laterally compressed, teliospores 1-celled, $24-31 \times 34-59 \mu$.

tsingchensis.

\section{On Juniperus sect. Oxycedrus}

1. Telia foliicolous, or on green stem, not causing hypertrophy of the stem.

2. Telia hemispheric or depressed-globose.

3. Teliospores with hyaline papillae over the pores.

4. Teliospores 35-49 $\mu$ long, papillae noticeable.

4. Teliospores 40-55 $\mu$ long, papillae large.

3. Teliospores without hyaline papillae.

torminali-juniperinum. davisii.

2. Telia pulvinate or applanate.

5. Teliospores with hyaline papillae.

5. Teliospores without hyaline papillae.

1. Telia caulicolous, causing witches' brooms. shiraianum.

1. Telia on twigs or branches, causing more or less hypertrophy.

6. Telia hemispheric, teliospores with carotiform pedicels.

6. Telia applanate or pulvinate, teliospores with terete pedicels.

7. Telia on smaller branches with slight hypertrophy.

8. Teliospores with hyaline papillae.

8. Teliospores without hyaline papillae.

7. Telia on larger branches with hemispheric or gall-like swellings.

6. Telia terete.

6. Telia conic or laterally compressed, higher than wide.

cornutum. corniforme. gracile.

clavipes.

1. Telia unknown; uredia present, teliospores intermixed, teliospores 2-celled.

cornutum. amelanchieris. tremelloides. clavariiforme.

\section{On Juniperus sect. Sabina}

1. Telia foliicolous, or on green stems, without hypertrophy.

2. Telia causing fasciation of branches (witches' brooms).

3. Telia hemispheric, teliospores medium-sized (37-52 $\mu$ long).

3. Telia bluntly conical, teliospores large (45-74 $\mu$ long).

nidus-avis.

kernianum.

2. Telia not causing fasciation of branches (or slight).

4. Telia arising between the leaves.

5. Pedicels of teliospores carotiform.

5. Pedicels of teliospores terete.

6. Pores 2 in each cell near septum, or only one in upper cell.

7. Teliospores subglobose $(25-30 \times 30-35 \mu)$.

inconspicuum.

gaeumanni. 
7. Teliospores ellipsoid $(17-27 \times 37-65 \mu)$.

6. Pores 5-7 in each cell, scattered.

4. Telia borne on the leaves.

8. Telia pulvinate, or hemispheric.

9. Teliospores ellipsoid $(15-27 \times 36-45 \mu)$.

9. Teliospores pastilliform $(20-39 \times 36-75 \mu)$.

8. Telia tongue-shaped or truncate.

10. Teliospores small $(18-23 \times 45-55 \mu)$.

10. Teliospores large $(16-22 \times 45-72 \mu)$.

1. Telia caulicolous, often causing witches' broom effect.

11. Telia cylindrical, teliospores $47-86 \mu$ long.

11. Telia hemispheric, teliospores $37-52 \mu$ long.

11. Telia hemispheric, teliospores 52-65 $\mu$ long.

1. Telia caulicolous, eausing more or less hypertrophy.

12. Telia on galls or gall-like excrescences.

13. Galls irregular, often breaking forth in succession along fusiform swellings, sometimes isolated.

13. Galls globoid, subgloboid, or reniform.

14. Telia laterally compressed.

15. Telia wedge-shaped.

16. Teliospores with papillae over pores.

16. Teliospores without papillae.

15. Telia irregularly compressed, often confluent.

betheli (or nelsoni). multiporum.

asiaticum (or nipponicum). formosanum.

exiguum.

harknessianum.

gracile. nidus-avis. vauqueliniae.

yamadae.

bosum.

nelsoni.

14. Telia terete, somewhat conic, chestnut-brown.

17. Teliospores with hyaline thickening over pores.

17. Teliospores without hyaline thickenings.

14. Telia subcylindric.

18. Telia cylindric-acuminate $10-20 \mathrm{~mm}$ long, golden-brown. juniperi-virginianae.

18. Telia mostly tapering, 6-10 $\mathrm{mm}$ long, chestnut-brown.

trachysorum.

14. Telia pulvinate.

19. Teliospores small $(18-25 \times 34-50 \mu)$, following aecia.

19. Teliospores medium $(23-29 \times 45-58 \mu)$, without aecia.

bermudianum.

turkestanicum.

12. Telia on fusiform swellings (sometimes on large branches or trunks).

20. Telia hemispheric, applanate, or pulvinate.

21. Pedicels of teliospores terete.

22. Pores 1, near the septum in lower cell, apical in upper cell.

22. Pores 2, near the septum, or 3 in upper cell with 1 apical.

exterum.

22. Pores 4 or more, near the septum, rarely or 1 or 2 additional above and below.

21. Pedicels of teliospores carotiform.

20. Telia cristiform, or erenate.

20. Telia wedge-shaped, often irregular and lacunose.

23. Teliospores medium-sized (42-55 $\mu$ long).

23. Teliospores large (57-66 $\mu$ long).

corniculans.

floriforme.

Telia conic or often laterally compressed, higher than wide.

24. Teliospores ellipsoid ( $30-60 \mu$ long).

24. Teliospores fusiform, falcate, or sigmoid (46-90 $\mu$ long).

20. Telia cylindrical, teliospores very long (up to $200 \mu$ ).

nidus-avis.

atlanticum.

clavipes.

speciosum.

effusum (or betheli). japonicum.

fuscum (or confusum). fusisporum. padmarense.

\section{On Libocedrus}

1. Telia foliicolous, pulvinate, teliospores 2-4-5-celled.

2. Uredial stage present, with numerous, conspicuous paraphysis-like structures.

2. Uredial stage unknown.

paraphysatum. libocedri. 


\author{
LEGENDS TO FIGURES
}

FIG. 1-4. Gymnosporangium, peridia of aecia showing variations in form and dehiscence (all somewhat enlarged). Fig. 1. Aecia cupulate, G. libocedri on Crataegus. Fig. 2. Aecia cornute, G. cornutum on Sorbus. FIg. 3. Aecia lacerate and spreading, G. confusum on Crataegus. Fig. 4. Aecia balanoid, G. fuscum on Pyrus (photo by V. Grasso).

Fig. 5-16. Gymnosporangium. FIG. 5-8. Variations in peridial cells of aecia (after Kern). Fig. 5. Verrucose (in part), G. inconspicuum. FIG. 6. Rugose, G. nidus-avis. FIG. 7. Spinulose, G. exiguum. FIG. 8. Smooth, G. hyalinum. FIG. 9-16. Variations in form of teliospores and uredospores. Fig. 9. G. gaeumanni. a. Two uredospores with thin walls; one with thick wall, amphispore. b. Two teliospores (after Zogg). FIG. 10. G. tsingchensis, teliospore with one cell. FIG. 11. G. biseptatum, teliospore with several cells (after Kern). FIG. 12. G. clavipes, teliospore with carotiform pedicel (after Kern). Fig. 13. G. ellisii, teliospore with linear-fusiform shape, several cells (after Kern). Fig. 14. G. davisii, teliospore with hyaline papillae over the pores (after Kern). Fig. 15. G. multiporum, teliospore with several seattered pores (after Bethel). Fig. 16. G. clavariiforme, teliospores with lanceolate shape, two cells (after Kern).

Fig. 17-24. Gymnosporangium globosum, aecial and telial stages. Fig. 17. Several groups of aecia with tubular peridia, becoming lacerate above, on leaf of Crataegus. Fig. 18. A peridium. Fig. 19. A straight, rugose peridial cell. Fig. 20. An aeciospore. Fig. 21. Photo graph of a globose gall on Juniperus. Fig. 22. Sketch of gall showing sears of telia of previous season. Fig. 23. A wedge-shaped telium. Fig. 24. A teliospore.

Fig. 25-32. Gymnosporangium juniperi-virginianae, aecial and telial stages. Fig. 25. An nular group of aecia with fimbriate and revolute peridia on leaf of Malus (after Kern). FiG. 26. Single peridium from above. Fig. 27. Aeciospore showing several pores. Fig. 28. A curved rugose peridial cell. Fig. 29. Subgloboid or reniform galls on Juniperus (after Kern). Frg. 30. Sketch of a gall showing collar-like swelling at base of each telium. Fig. 31. A cylindricacuminate telium. Fig. 32. A teliospore.

FIG. 33-37. Gymnosporangium, showing varied distribution of sori-four telia, one aecium (after Kern). Fig. 33. Telia foliicolous, pulvinate, G. libocedri. Fig. 34. Telia foliicolous, hemispheric, G. davisii. Fig. 35. Telia on a gall, irregularly compressed, often confluent, $G$. nelsoni. Fig. 36. Aecia on a gall, cylindric, G. bermudianum. Fig. 37. Telia on gall-like exerescences, terete, somewhat conic, G. corniculans.

FIG. 38-41. Gymnosporangium, effects on hosts produced by the telial stages. Fig. 38. Telia causing fasciation of the branches, G. kernianum (after Kern). Fig. 39. Telia on fusiform enlargement, applanate, G. exterum (after Kern). Fig. 40. Telia on slight fusiform swellings, pulvinate, G. cornutum (after Oersted). Fig. 41. Telia on irregular enlargement, applanate, G. tremelloides (after Kern).

FIG. 42, 43. Gymnosporangium clavariiforme, telia on gradual fusiform enlargements, terete or slightly compressed. Fig. 42. Telia mature but dry. Fig. 43. Telia after swelling in moisture. 

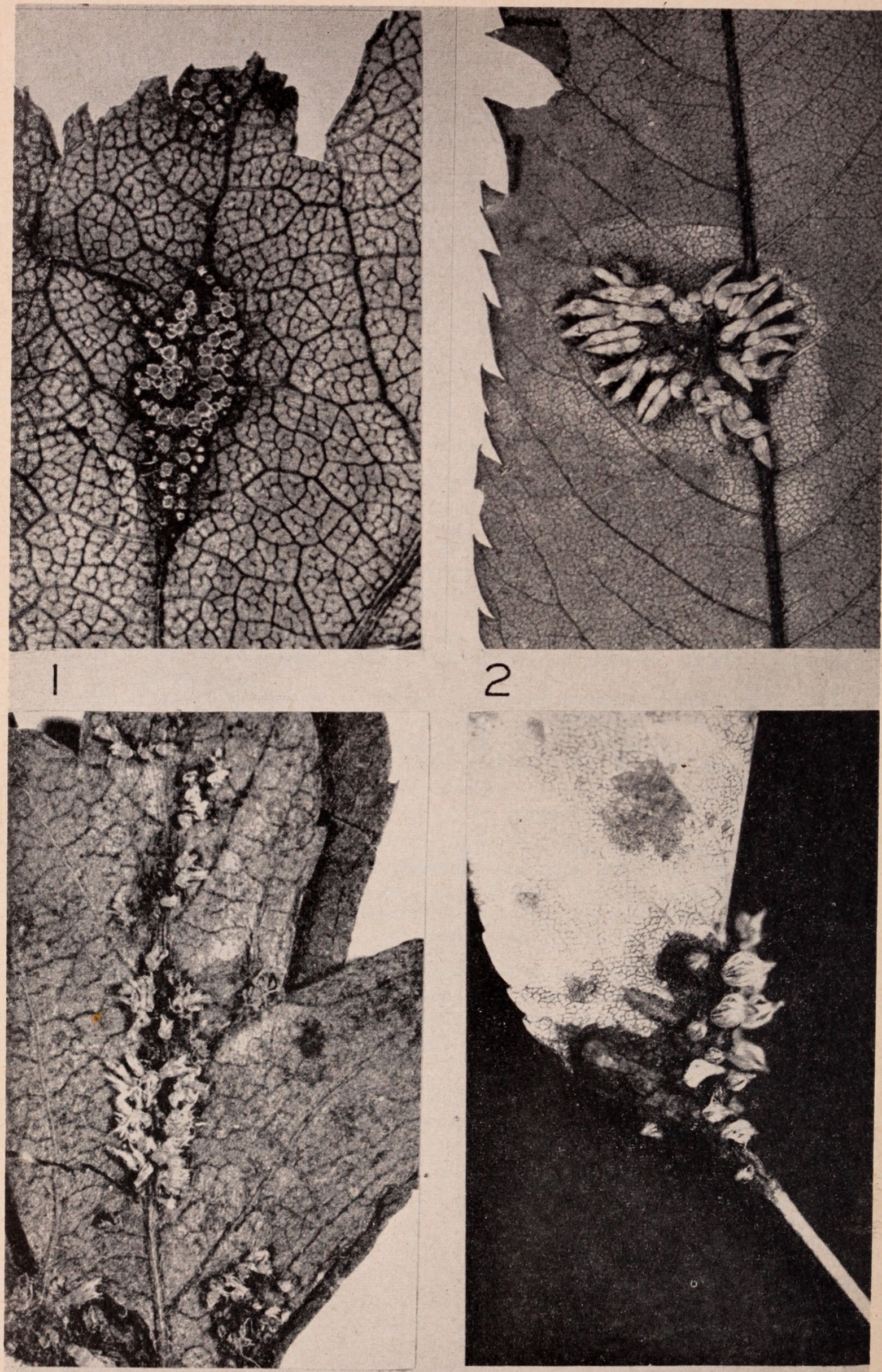

3

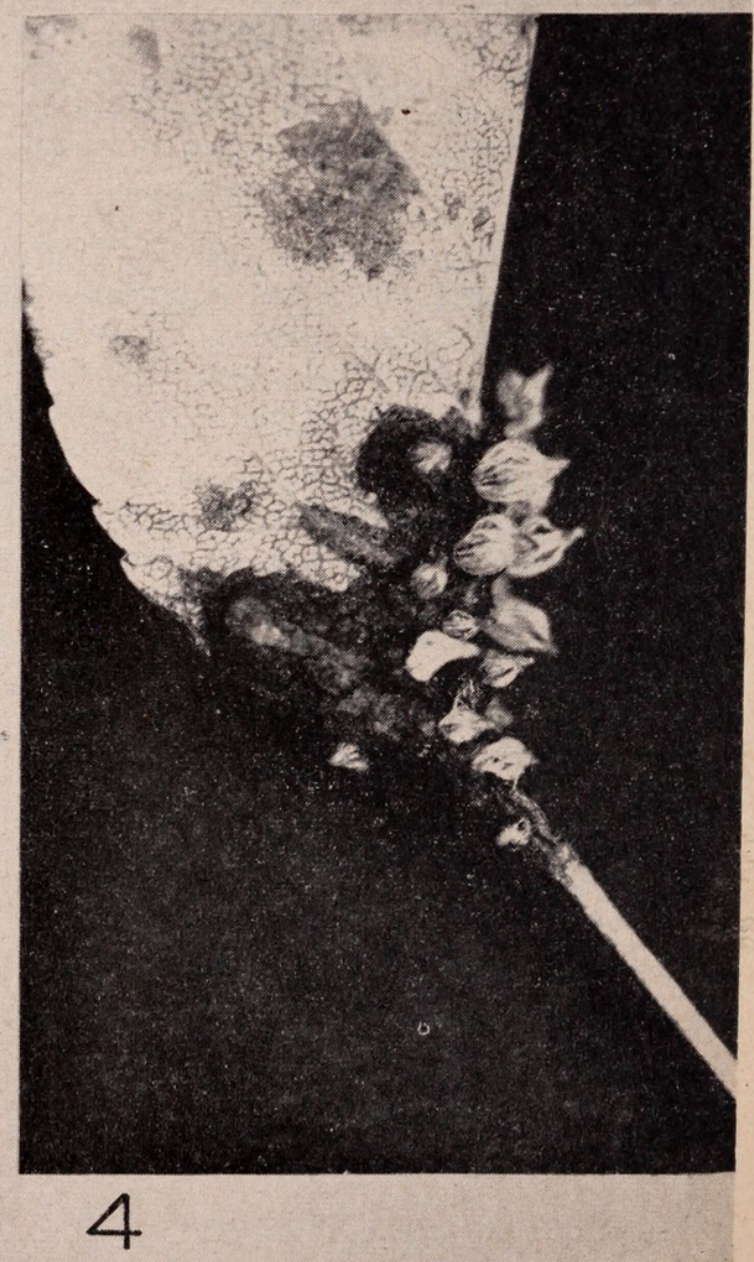



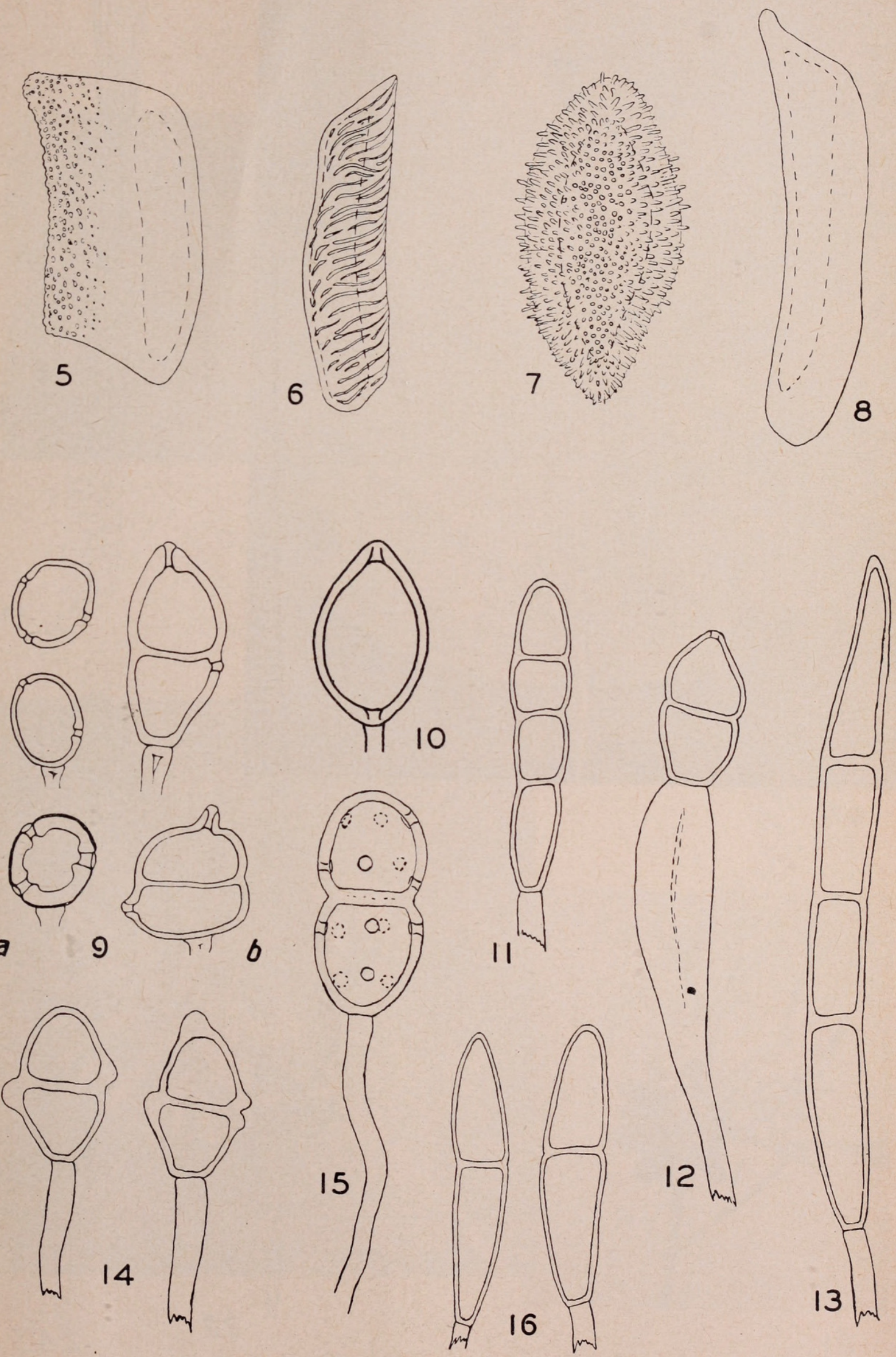

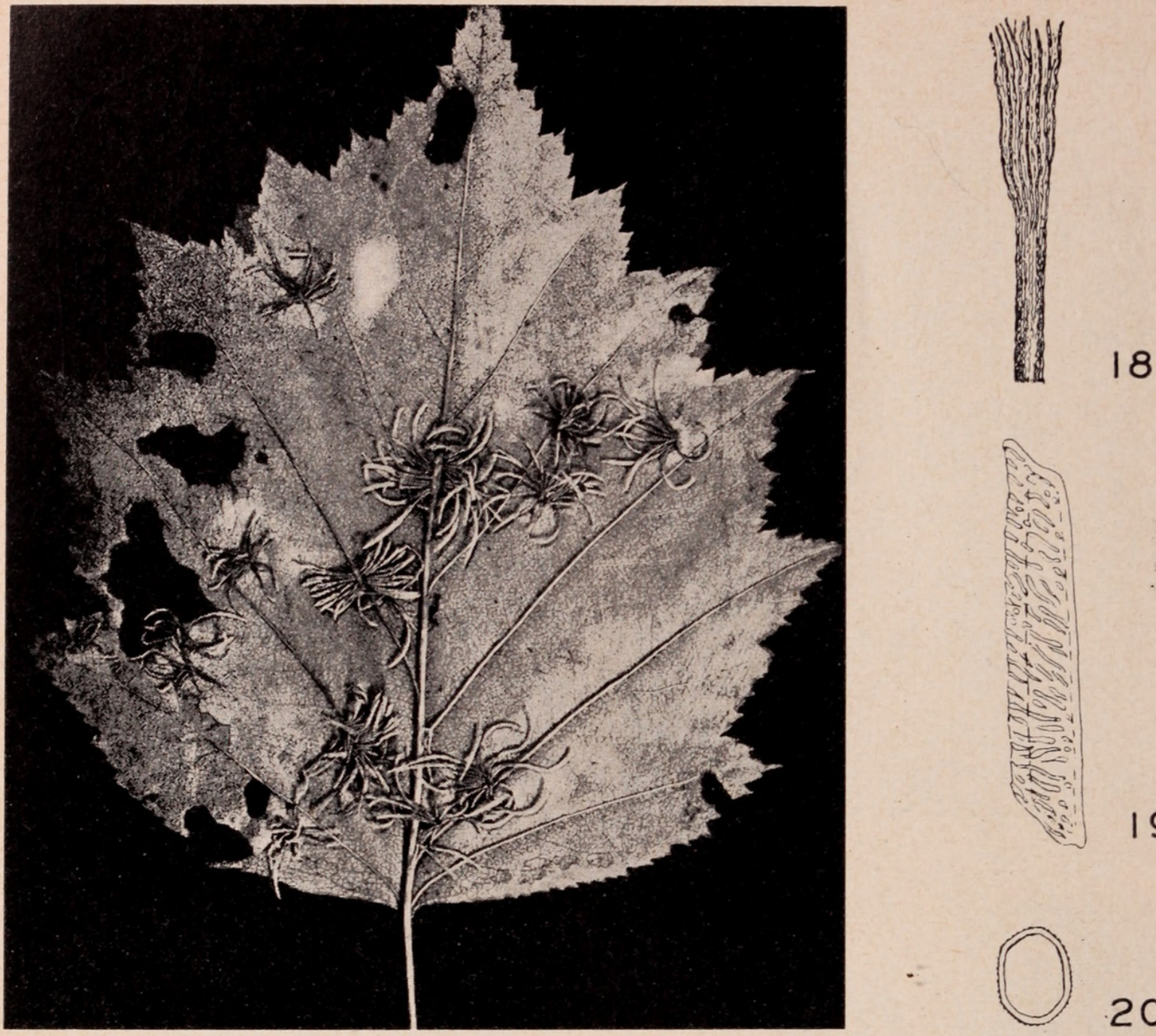

17

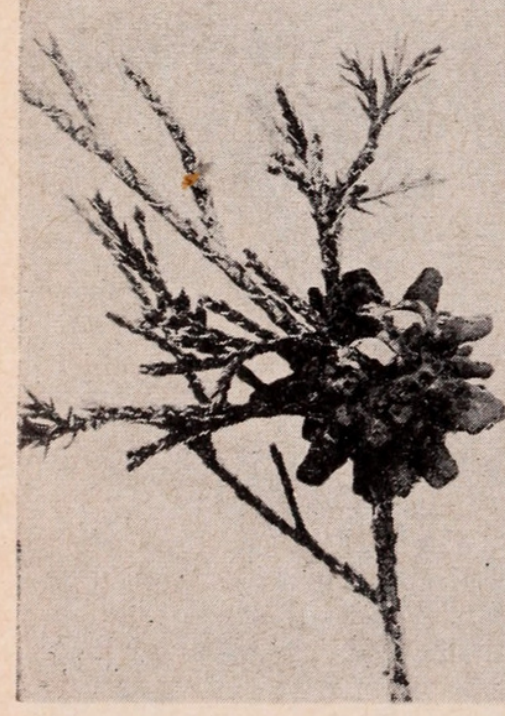

21
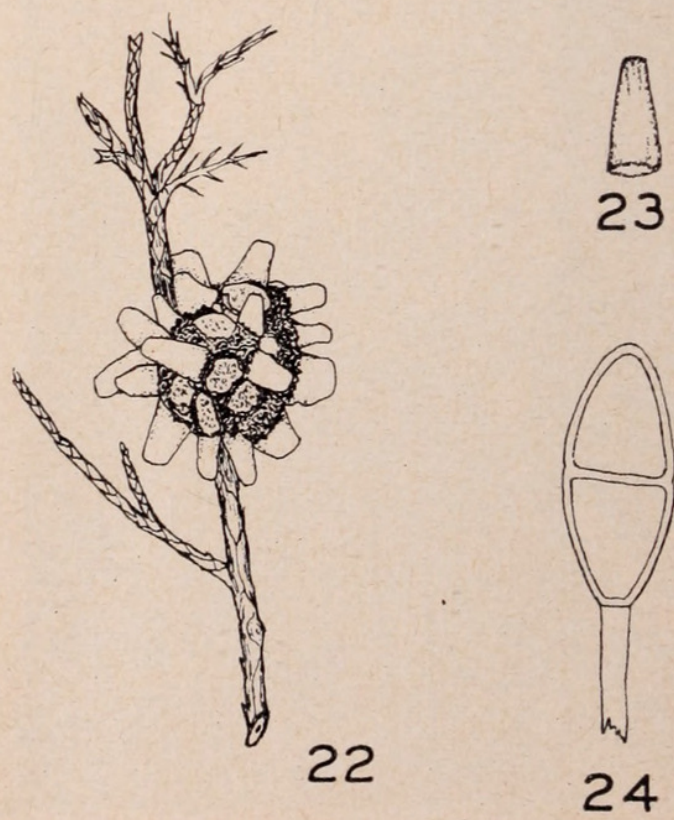


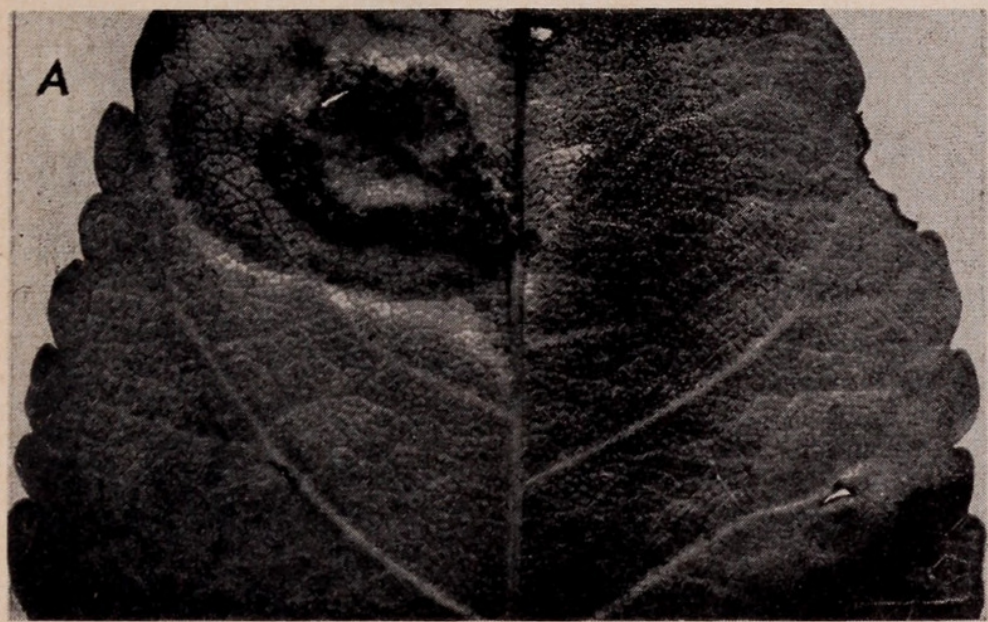

25

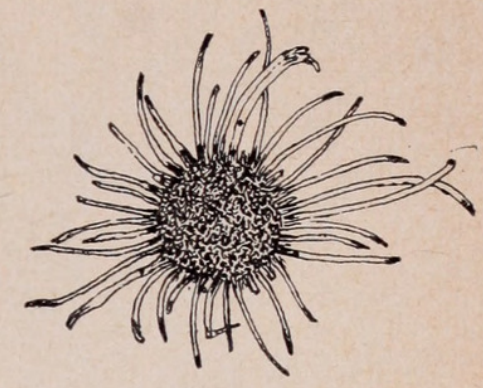

26
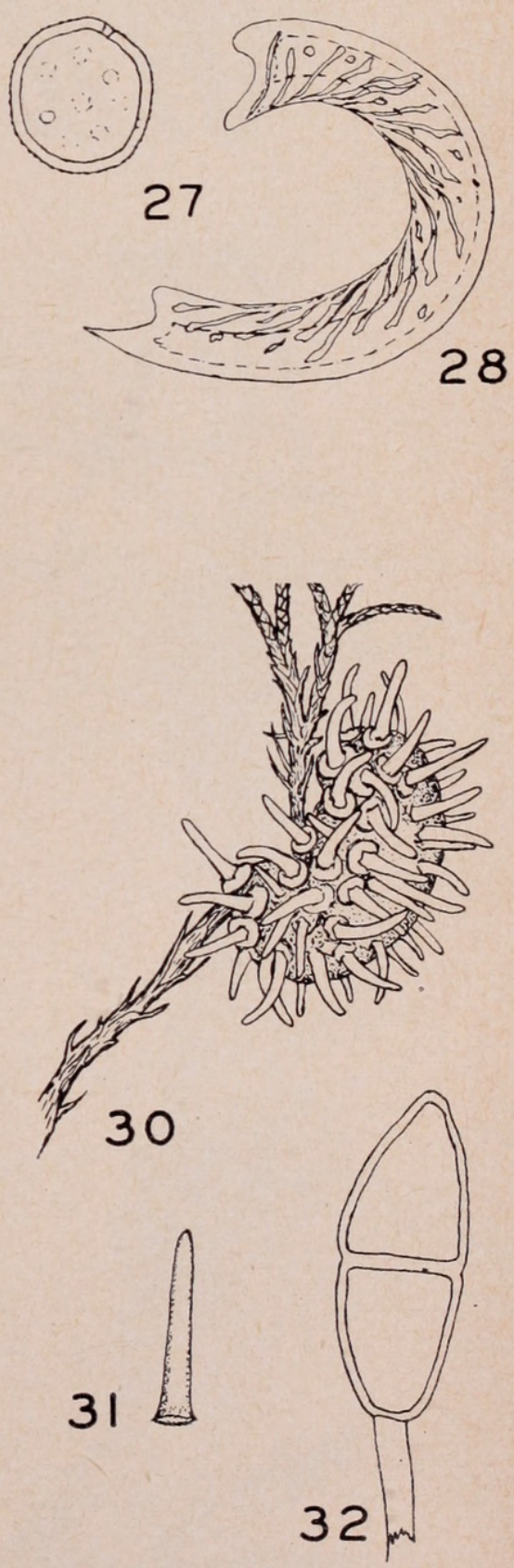

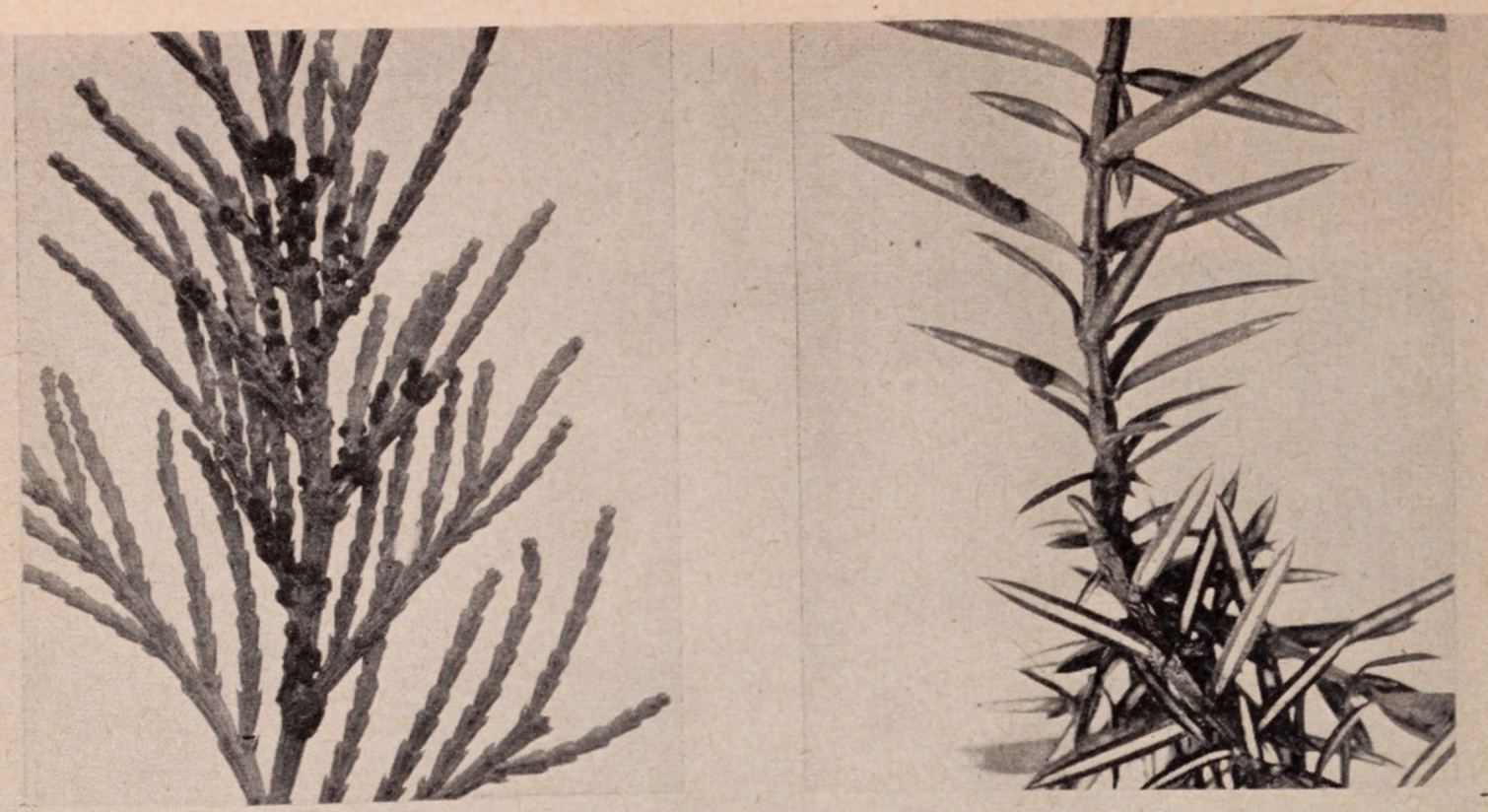

33
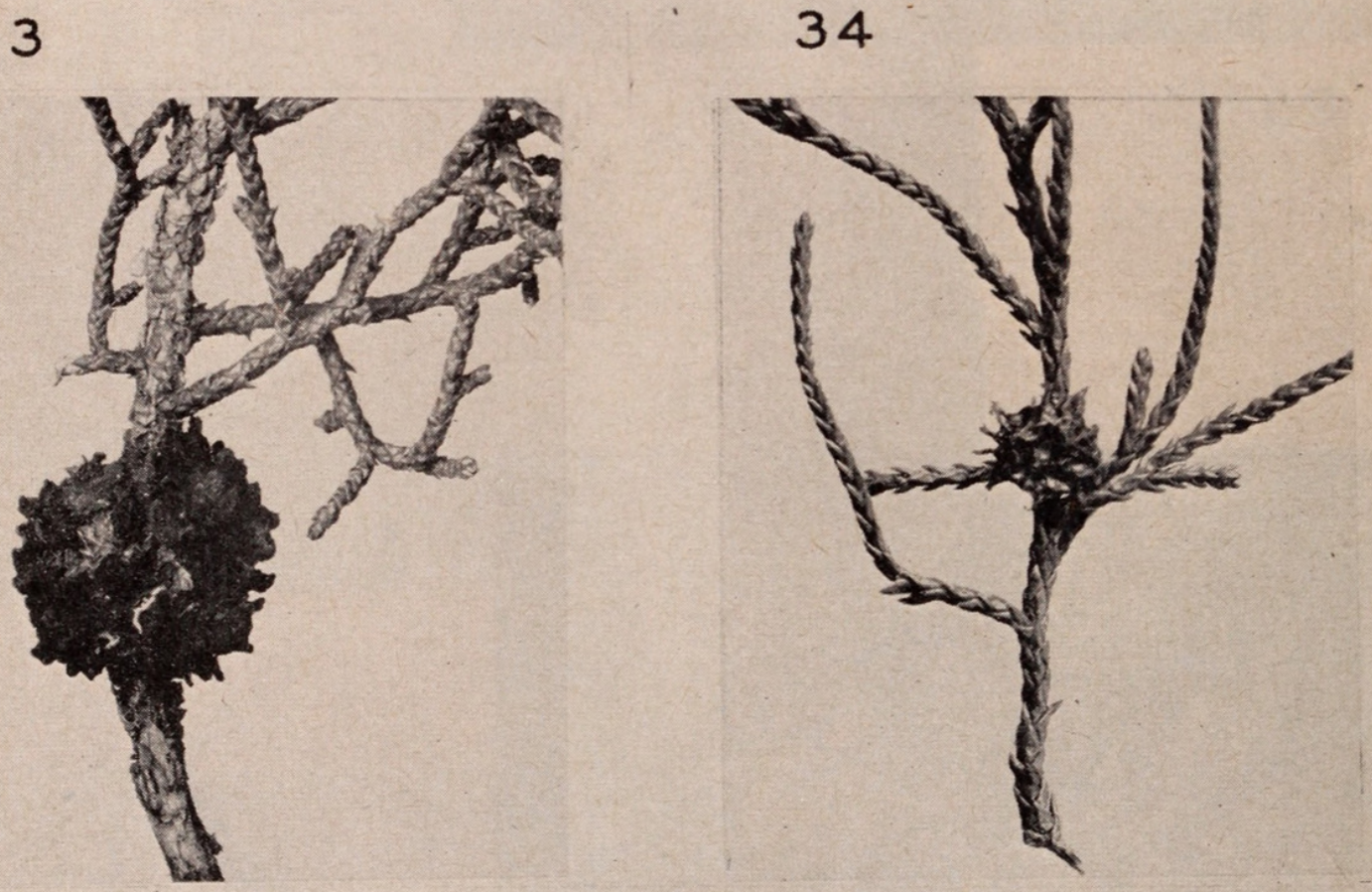

35

36

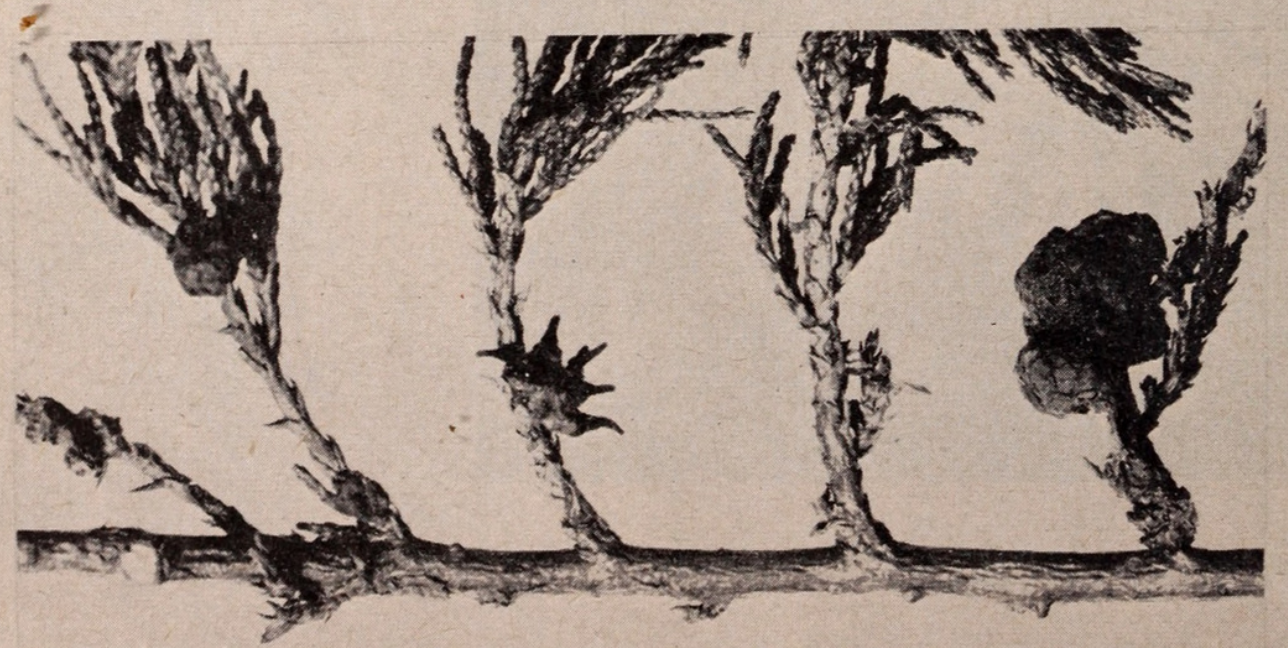




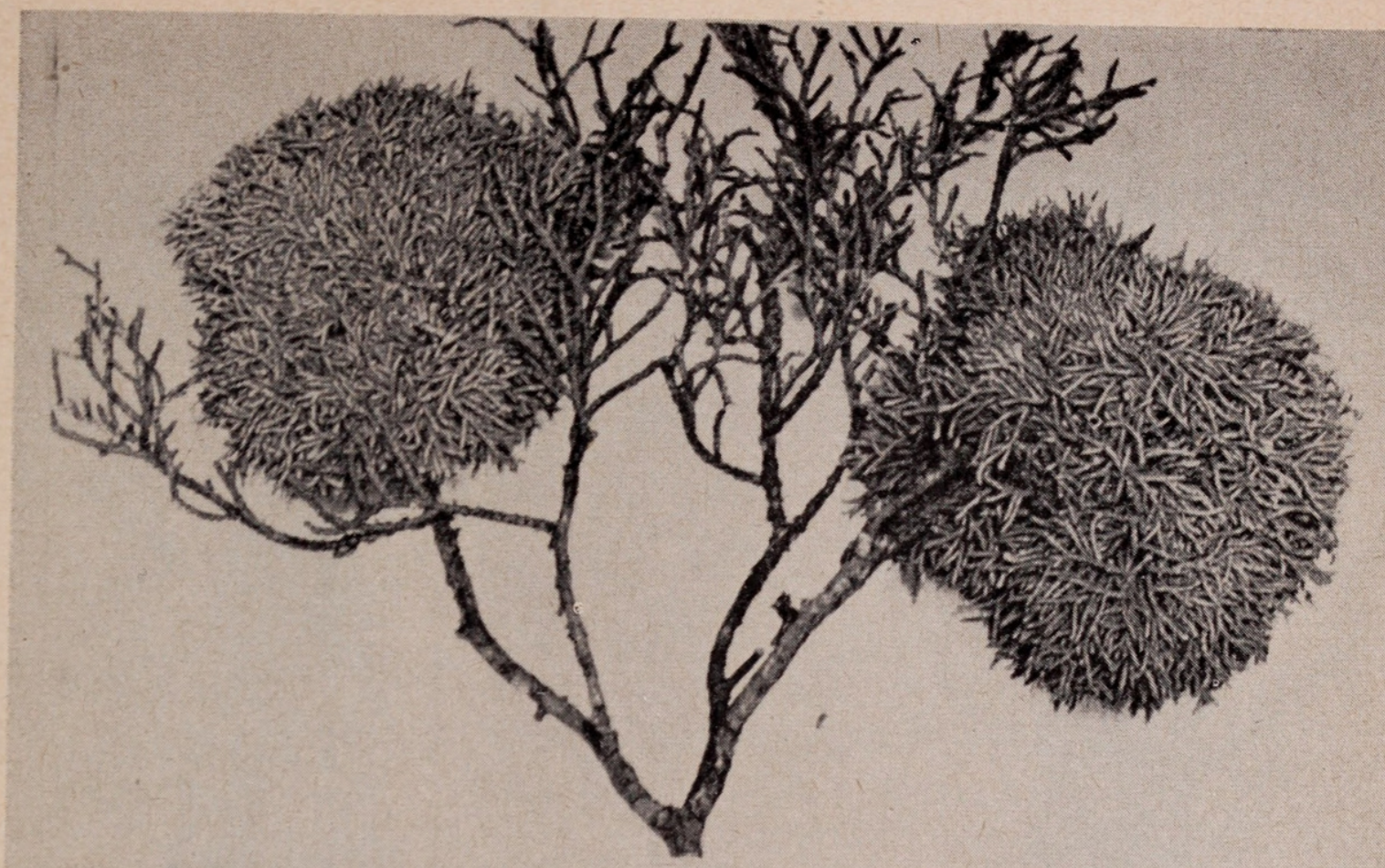

38
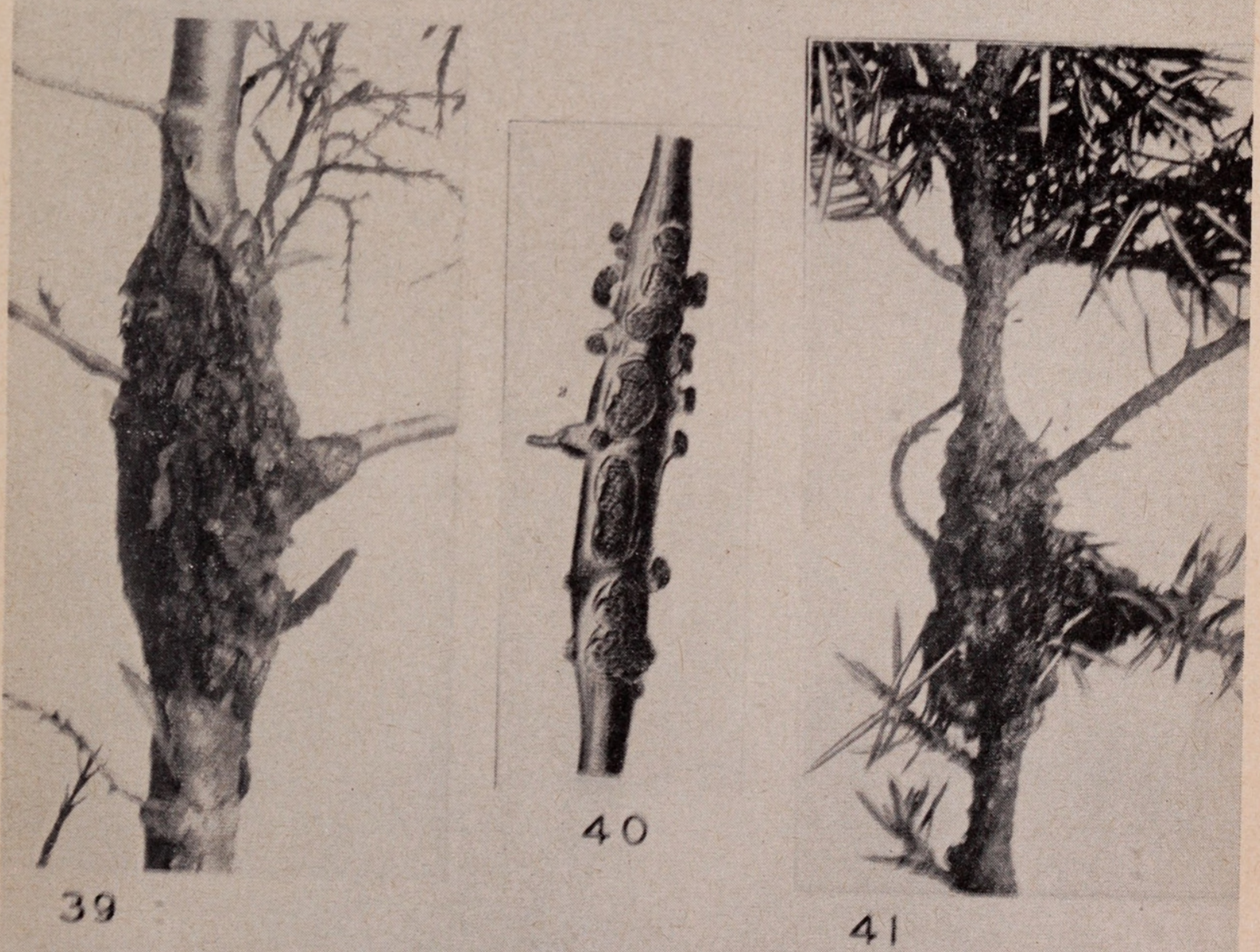


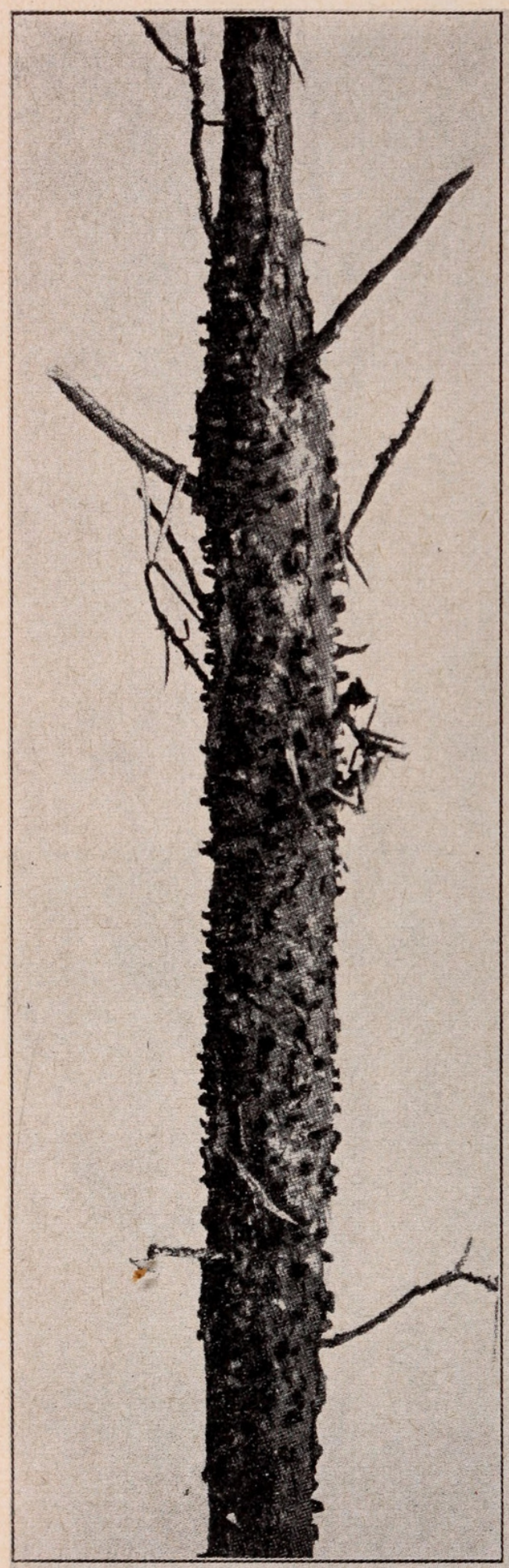

42

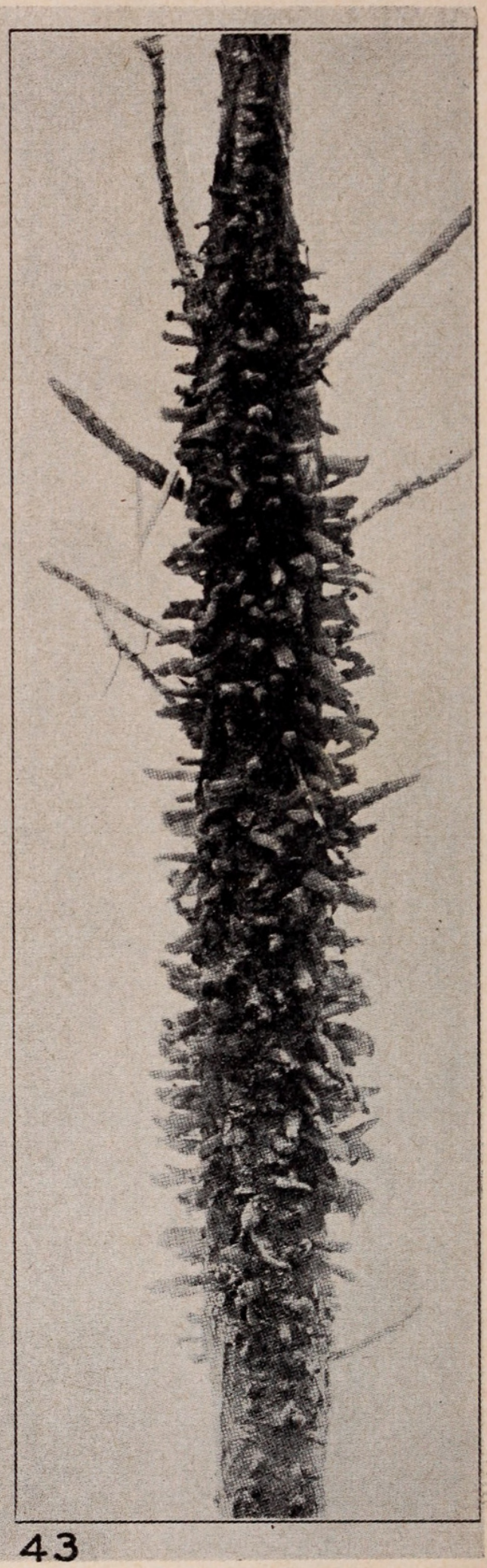




\section{$2 \mathrm{BHL}$ Biodiversity Heritage Library}

Kern, Frank D. 1964. "Lists and keys of the cedar rusts of the world." Memoirs of the New York Botanical Garden 10(5), 305-326.

View This Item Online: https://www.biodiversitylibrary.org/item/150908

Permalink: https://www.biodiversitylibrary.org/partpdf/324555

\section{Holding Institution}

New York Botanical Garden, LuEsther T. Mertz Library

\section{Sponsored by}

BHL-SIL-FEDLINK

\section{Copyright \& Reuse}

Copyright Status: No known copyright restrictions as determined by scanning institution. License: https://biodiversitylibrary.org/permissions

This document was created from content at the Biodiversity Heritage Library, the world's largest open access digital library for biodiversity literature and archives. Visit BHL at https://www.biodiversitylibrary.org. 